\title{
Structural Analysis of Fragments of the Broken Coat of a Cylinder which Led to the Dismantling of a Combustion Engine
}

\author{
FLORENTINA POTECASU ${ }^{1}$, MARIAN BORDEI ${ }^{1 *}$, ION SANDU2,3 \\ 'Dunarea de J os University of Galati, Faculty of Engineering, 111 Domneasca Str., 800008, Galati, Romania \\ ${ }^{2}$ Alexandru Ioan Cuza University of lasi, ARHEOINVEST Interdisciplynary Platform, 22 Carol I Blvd., Corp G, 700506, Iasi, \\ Romania \\ ${ }^{3}$ Romanian Inventors Forum, 3 Sf. Petru Movila Str., BI. L11, Sc. A., III/3, 700089, Iasi, Romania
}

\begin{abstract}
The paper presents the structural analysis of cast iron fragments from the cylinder coat of a combustion engine, as a result of the broken down through explosion. Initially, determinations of the chemical composition were made and it was found that although the cast iron had the carbon content imposed. As a result, detailed microstructural analyzes were made regarding the shape, size and distribution of graphite in the cast iron as well as for the identification of structural constituents and constitutive phases. The same investigations were carried out on samples taken from a cylinder coat with a good functioning for comparison (blank samples). The metallographic study revealed characteristics of inappropriate graphite separations (graphite type $B, D, E$ ) and areas with specific structural constituents to the mottled cast iron that can cause breakage of the cylinder coat and excessive wear of the segments.
\end{abstract}

Keywords: microstructural analysis, combustion engine, chemical composition, metallographic study, mottled castiron

The material of the cylinder coat must provide the necessary resistance to dynamic and static stresses and especially to wear, taking into account the operation in particularly unfavorable friction conditions. Most often, the most commonly used material is gray cast iron alloyed with elements such as $\mathrm{Si}, \mathrm{Cu}, \mathrm{Cr}, \mathrm{Mo}, \mathrm{Mn}$, which increase its wear resistance. The process of making of the cylindrical coats is, usually, centrifugal casting, followed by honing, chroming, nitration or phosphating [1-8].

Grey iron cast crystallize, partially or totally, according to the Fe-graphite system. They contain the undissolved carbon in the iron, partially or totally, in the form of graphite. Grey iron cast are the most used casting alloys, having a low cost, good machinability, vibration damping capacity, lubricating properties under dry rubbing conditions, corrosion resistance.

Industrial grey cast iron is hypoeutetic, with structure: ferritic, ferrite-perlite, perlitic, perlite-cementitious or phosphorous-grey cast iron; there are classified according to the chemical composition, the nature of the metal mass, the distribution mode and the graphite form. The distribution of lamellar graphite can be uniform, in rosettes, uneven, interdentritically oriented or non-oriented. The shape of the graphite varies from the lamellar with sharp tips, typical of the common grey cast iron to the lamellar one, with rounded tops, vermicular, in the nest and nodular [9-15].

The structure and properties of the cast iron depend on graphite germination capacity. The graphite comes either directly from the liquid and solid phase, or from the decomposition of the cementite. The factors influencing the graphite separation in the liquid phase are: the chemical composition of the castiron (through the action of graphite elements C, Si, Cu, Al, Ni or Mn, Cr, Mo, V), cooling rate and germination capacity of the melt. By varying the silicon content or the cooling rate, we can get the whole range of cast iron, from the white to the gray ferite ones.

Common grey cast iron, with sharp-edged lamellar graphite has low strength and tenacity properties, due to the increasing effect introduced by the graphite separation tip. This effect is reduced by altering the shape and dimensions of the graphite separations $[9,10,16]$.

Common grey iron cast has good casting properties, lower solidification shrinkage than steels, high fluidity, which allows the production of thin-walled pieces, complex shapes that are unreachable by mechanical methods; the mechanical characteristics of strength and tenacity are inferior to steels due to the presence of graphite. However, graphite ensures a good machinability, high vibration damping capacity, lubricating properties under dry rubbing conditions, insensitivity to notches, corrosion resistance in the usual corrosive environments $[9,17-20]$.

The aim of the present study had as a starting point of the catastrophic and unexpected broken down of the cylinder and of the ring of the cylinder coat (in order to determine the causes of its failure and the excessive wear of the segments)

\section{Experimental part}

\section{Materials and methods}

The cylindrical coats analyzed in this paper are made of hypoeutetic iron with $2.8 \% \mathrm{C}$. Samples were taken for microstructural analysis from a well-functioning cylinder coat, samples used as a blank samples (series A) and samples from fragments resulting from the explosion of a cylinder coat from a combustion engine (B series). In order to establish the chemical composition-structure-property correlation, first chemical analyzes were made using an $X$-ray fluorescence spectrometer, provided by the material characterization laboratory for both series of materials. The chemical composition of the blank samples, A series, showed the presence of the following alloying elements: $\mathrm{Si}=2.46 \%, \mathrm{Cu}=0.27 \%, \mathrm{Mo}=0.43 \%, \mathrm{Mn}=0.53 \%, \mathrm{Cr}$ $=0.35 \%$. In the of the castiron of the cylinder coat degraded through explosion, B series, the folloing quantitites for alloying elements: $\mathrm{Si}=2.28 \%, \mathrm{Cu}=0.41 \%, \mathrm{Mo}=0.19, \mathrm{Mn}$ $=0.55 \%, \mathrm{Cr}=0.54 \%$ were determined. The carbon content, in the two series of materials, is the one required to the

\footnotetext{
* email: marian.bordei@ugal.ro
} 
manufacturer, so that, by the influence of the alloying elements on the structural constituents from the base mass of the cast iron, the desired structure must be obtained.

Analysis of samples prepared metallographically but without metallographic attack

Figure 1 shows the microstructural analysis of the analyzed materials. For B series, samples from the fragments resulting from the explosion (B1 series) as well as from a crackles area (B2 series) were analyzed.

Figure 1 shows the 100:1 microscope magnification, the analyzed samples microstructures (A series, B series) illustrating the appearance, shape, size and distribution of graphite in the base mass of the cast iron product.

Figure 1 shows that, for the series taken as a blank samples, the A series, the graphite is dispersed almost uniformly in the foil metal matrix (in the section it appears as slightly curved blades). The $\mathrm{B}$ series samples highlight graphite with interdentritic layout consisting of fine separations that tend to compaction in nests (highlighted in 400:1 magnification in Figure 1c of the B series). Such a graphite distribution involves a high cooling rate but also a higher amount of phosphorus in the cast iron. Another explanation would be that the solidification of the marker (the cylinder coat) led to heterogeneous structures (structural inhomogeneity in the thickness of the wall) with the formation of free carbides of the alloying elements and, probably, an atypical eutectic (containing together with graphite eutectic and secondary graphite and alloyed carbides). In this case, you might be talking about a mottled

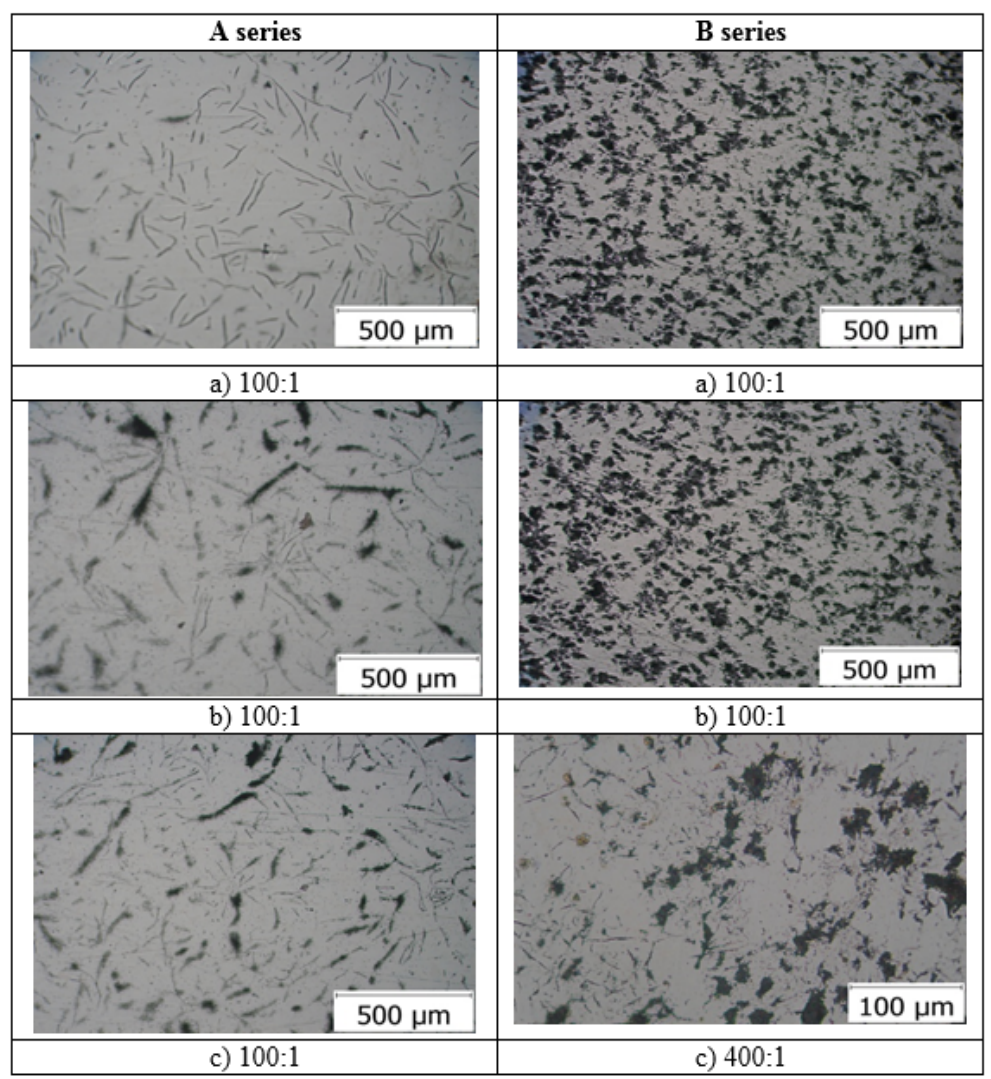

cast iron, a situation that would seriously lead to a high fragility of the material at strain which could cause tearing.

The presence of graphite in the base mass gives the grey appearance of the breaking surface and hence the name of the cast iron. When in the base mass, graphite and also free microvolumes of $\mathrm{Fe}_{3} \mathrm{C}\left(\mathrm{Fe}_{3} \mathrm{C}_{\|}\right)$are included, the cast iron is called mottled cast iron, and in the gap it can be noticed bright microvolumes [2]. This was also observed in fractures of fragments resulting from the explosion.

Figure 1 illustrates that for A series, the graphite is dispersed almost uniformly in the metal matrix in the form of sheets (in the section it appears as slightly curved blades). B series samples highlight a graphite with interdentritic layout consisting of fine separations that tend to compaction in nests (aspect emphasized at the $400 \mathrm{x}$ enlargement in figure $1 c$ of the $B$ series). Such a graphite distribution involves a high cooling rate but also a higher amount of phosphorus in the castiron.

Figure 2 presents the standardized aspects for the graphite types identified in the series of analyzed samples. The A series presents a uniformly distributed graphite (type A), and the B series highlights graphite in rosettes (type B), and oriented interdendritic graphite (type E) and nonoriented interdendritic graphite (type D).

Graphite provides a good machining, high vibration damping capacity, lubricating properties under dry friction conditions, insensitivity to notches, corrosion resistance in common corrosion environments.
Fig.1. Microstructure of cast iron samples from different areas (without metallographic attack):

A series - well-tested drum shroud (blank samples); B series - samples from the debris of the cylinder coat broken down by the explosion

\begin{tabular}{|c|c|c|c|}
\hline $\begin{array}{c}\text { Uniformly } \\
\text { distributed graphite } \\
\text { (type A) }\end{array}$ & $\begin{array}{c}\text { Graphite in rosettes } \\
\text { (type B) }\end{array}$ & $\begin{array}{c}\text { Non-oriented } \\
\text { interdendritic } \\
\text { graphite (type D) }\end{array}$ & $\begin{array}{c}\text { Oriented } \\
\text { interdendritic graphite } \\
\text { (type E) }\end{array}$ \\
\hline & & & \\
\hline & & & \\
\hline & & &
\end{tabular}

Fig. 2. Standardized graphite distribution patterns in the analyzed casting [1] 


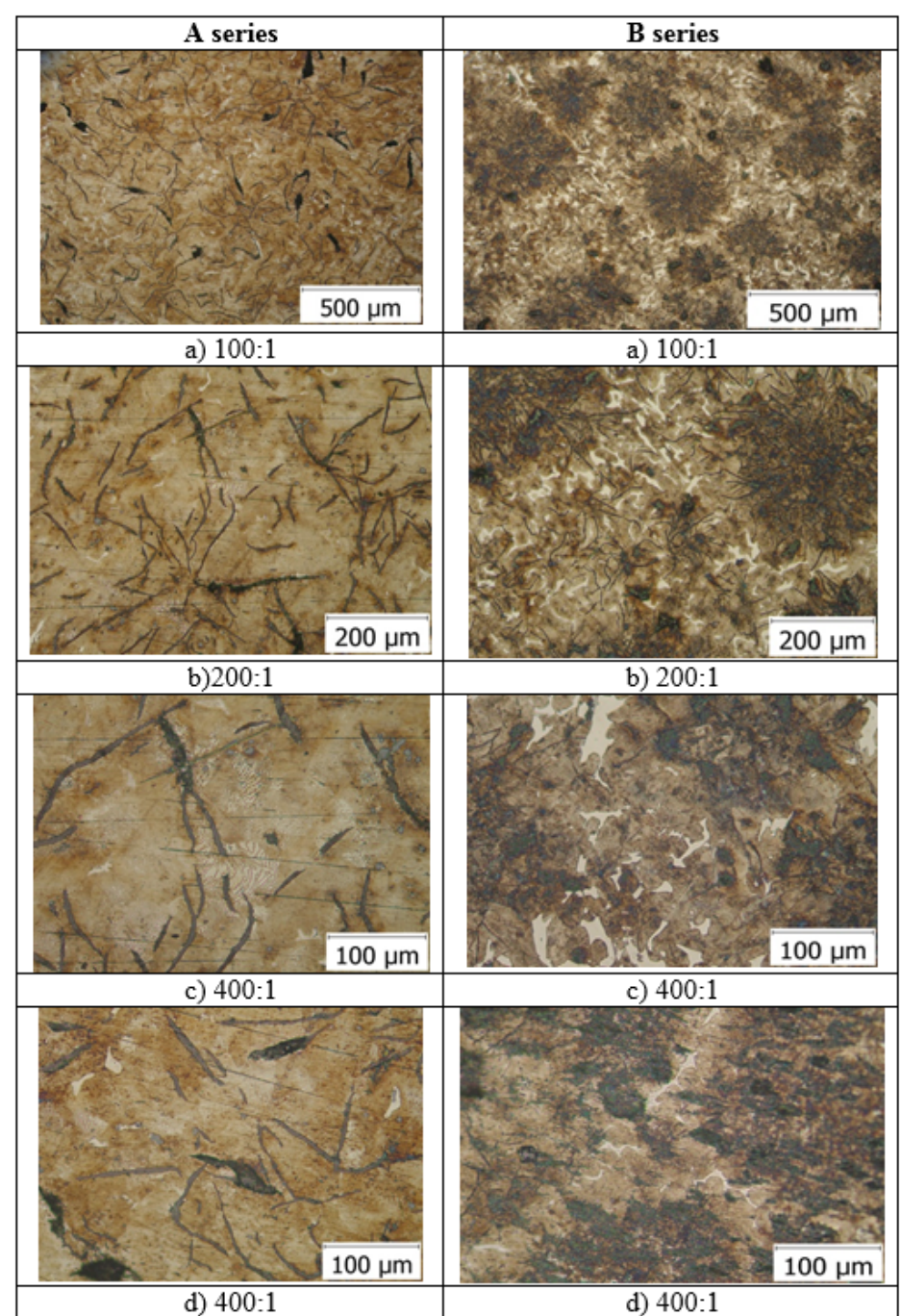

The best mechanical properties correspond to the type A distribution (fig. 1) found in the A series with a good running behavior. In conclusion, in B series with undesirable behavior, the graphite distribution was not the optimal one (type A).

By altering the conditions of molding and casting and by heat treatment, the quantity, size, shape and distribution of graphite can be obtained with positive effects on the mechanical characteristics and application area.

Analysis of microstructures of analyzed samples prepared metallographically and attacked with metallographic reagent

The microstructural analysis of the metallographically prepared samples and attacked with the metallographic reagent ( $3 \%$ nitric acid in ethyl alcohol), was performed on an Olympus metallographic microscope with digital image acquisition and Optica Vision processing software.

Figure 3 presents the structural constituents for the two series of analyzed samples, highlighted after metallographic preparation by attack with the specific metallographic reagent, Nital (3\% nitric acid in ethyl alcohol).

The microstructural analysis of the sample set $A$, shown in the microstructures of figures $3 a, 3 b, 3 c$ and $3 d$, shows a gray phosphorous castiron with perlite base mass. In the perlite matrix there is $1 . . .2 \%$ eutectic phosphorus, known as steadite state, $E_{f}\left(F_{3} P+F e_{3} C+P\right)$, with a metallographic aspect of lace. Phosphorus is a poorly grafted element in the primary crystallization of the cast iron and antigrafitization to the secondary crystallization. It is found a part dissolved in the ferrite that hardens and another part
Fig. 3. Microstructure of casting samples taken from different areas (metallographic attack).

A series - well-tested drum shroud (blank samples); B series - samples from the debris of the cylinder coat broken down by the explosion in the form of the eutectic ternary $E_{f}\left(P+\mathrm{Fe}_{3} \mathrm{C}+\mathrm{Fe}_{3} P\right)$, called eutectic phosphorus or steadite.

This eutectic has a low melting temperature $\left(\approx 950^{\circ} \mathrm{C}\right)$, is intercrystallinelly spread and has a high hardness (400$600 \mathrm{HB}$ ). In grey cast iron, the eutectic in small quantities and finely and evenly dispersed in the metallic mass, improves mechanical strength, hardness, abrasive wear resistance and casting properties. Phosphorous grey cast iron, containing up to $1.5 \% \mathrm{P}$, is used to cast thin-walled parts (radiators, bath tubs, cylinder coats) or abrasive wear resistant products (brake shoes, piston segments) The phosphorus eutectic in the A series samples is uniformly and finely dispersed in the metal matrix. Series B samples highlight distinctly different aspects. At small magnifications $100 x, 200 x$, a white network, discontinuous is revealed in the perlite matrix, around the former austenite crystals or around the graphite separations. At big magnifications, 400x , it is found there is a non-uniformly eutectic phosphorus disposed unevenly (sometimes in thick network, in open separations or even in a discontinuous network, open by secondary cementite (free)), or an atypical eutectic with both forms of carbon as constitutive phases dispersed in the perlite matrix, carbides and graphite, E[P+ Graphite + Allied Carbides +Grafit $]$ and even ledeburita, which makes these cast iron to be found in the group of perlite-cementite gray or mottled cast iron.

The structural constituents highlighted in the B-series structure lead to a pronounced hardening of the cast iron and an accentuation of the fragility of the parts, which can explain the catastrophic rupture by explosion. 

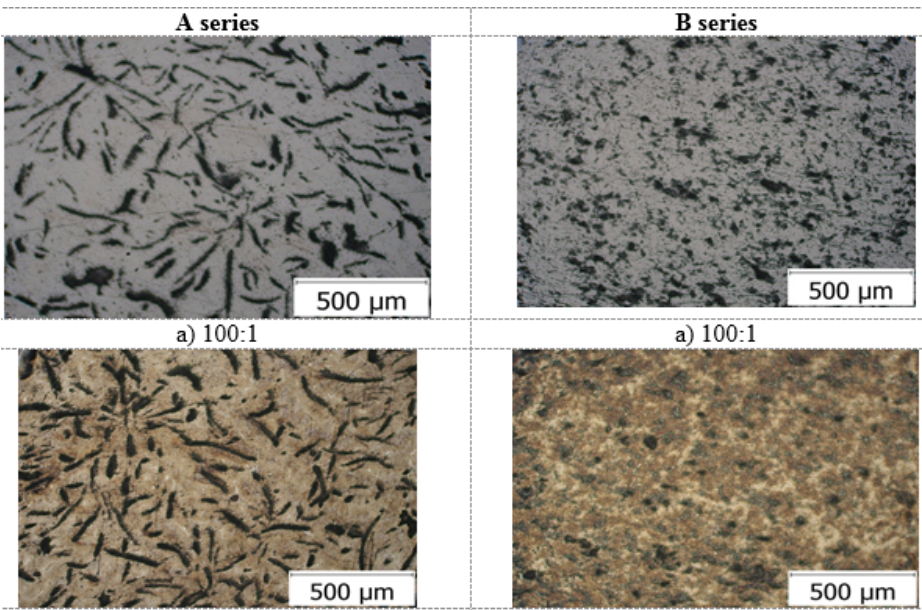

b) $100: 1$

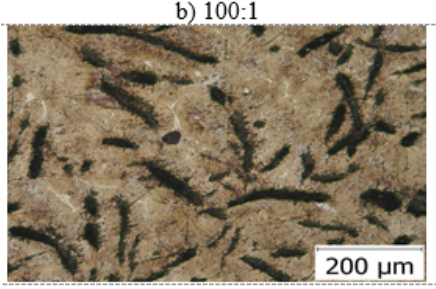

c) $200: 1$

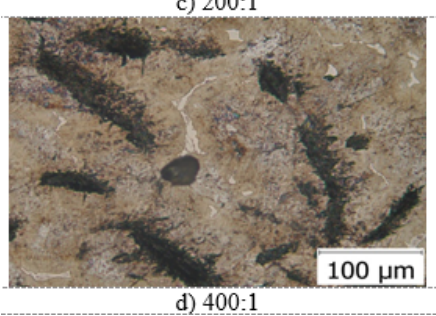

Fig. 4. Microstructure of cast iron samples from different areas (in cross section through the thickness of the cylinder coat). A Series - well-tested drum shroud (blank samples); B Series - samples from the debris of the cylinder coat broken down by the explosion (without metallographic attack, b, c, d - with metallographic attack)

Figure 4 shows the microstructural aspects for the two series of analyzed materials, executed in cross section through the cylinder coat. The same aspects as in the longitudinal sections show $n$ in figures 1 and 3 are highlighted. The graphite is not of the type A, uniformly dispersed in lightly curved finishes (as in A series), the amount of eutectic ternary phosphorus, $E_{f}\left(P+\mathrm{Fe}_{3} \mathrm{C}+\right.$ $\mathrm{Fe}_{3} P$ ), the steadite state is $1 \ldots 2 \%$ finely dispersed in the base perlite mass (A series) and much larger and unevenly distributed in the B series. Additionally, in B series primary and secondary alloy carbides are released in the perlite.

If at A series, the eutectic consists of perlite and graphite $E_{\text {seria a }}\left[P\left(F+F_{3} \mathrm{C}\right)+G_{\text {eutecticic }}+G_{\text {secondarty }}\right]$, in the case of B series, the eutectic is characteteristic to the mottled cast iron of $E_{\text {seria B }}\left[P\left(F+\mathrm{Fe}_{3} \mathrm{C}\right)+G_{\text {eutectic }}+\right.$ Carbides $\left._{\text {secondary }}+G_{\text {secondary }}\right]$ and determines the fragilitity of the material, as shown in figure 5.

Following the application, cracks were created from the steadite state separations, loose, eutectic atypical carbons, which developed through the intercrystalline coarse network.

\section{Conclusions}

A series presents a uniform distributed graphite (type A), and B series highlights a graphite in rosettes (type B), oriented interdendritic graphite (type E) and non-oriented interdendritic graphite (type D);

The microstructure of the attacked samples revealed for the series A of samples a pearlitic lamellar gray cast

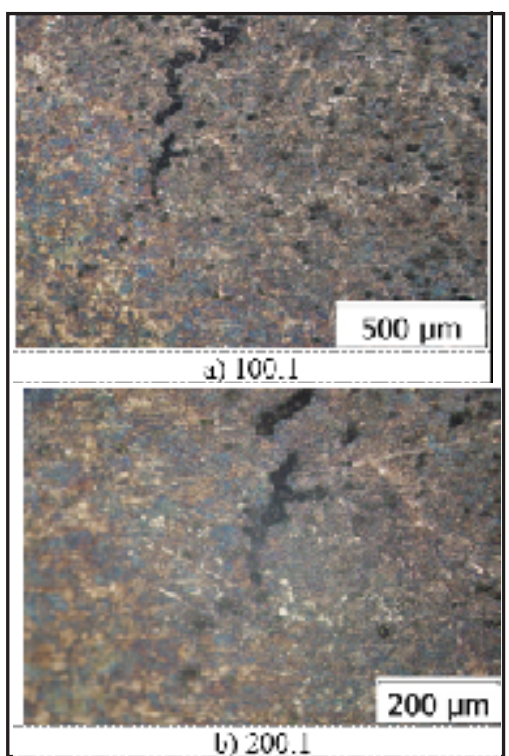

Fig. 5. B-series microstructures with metallographic attack in the broken cylinder (developed on the intercrystalline network)

iron structure, with 1-2\% fine phosphorus eutectic, evenly distributed in the metal matrix;

For the series of B samples, there is a mottled cast iron (perlite-cementitious) structure with an open, sometimes gross, interdendritic network, consisting of eutectic ternary phosphorus and eutectic atypical gray iron ( $P+$ carbides + graphite), free cementite and sometimes even ledeburit which caused the cast iron to be very hard and brittle.

The structure of the $B$ series was favored by a lower amount compared to the chemical composition of the A series, of the grafitizing elements (especially Si) and the larger amount of the antigrafitization and carburigens ( $M n$, $\mathrm{Cr}$ ), which led to the formation of free ally carbides in the network.

\section{References}

1.ROSCA, R., RAKOSI, E., MANOLACHE, G., ROSU, V., Elemente de tehnologia autovehiculelor, Ed. Politehnium Iasi, 2005.

2.POPA, B., BATAGA, N., CAZILA, A., Motoare pentru autovehicule, Ed. Dacia, Cluj-Napoca, 1982.

3.SANDU, A.V., CIOMAGA, A., NEMTOI, C., BEJ INARIU, C., SANDU, I., J ournal of Optoelectronics and Advanced Materials, 14, no. 7-8, 2012, p. 704.

4.SANDU, A.V., CODDET, C., BEJ INARIU, C., J. Optoelectron. Adv. M., 14, no. 7-8, 2012, p. 699.

5.SANDU, A.V., CIOMAGA, A. NEMTOI, G., ABDULLAH, M.M.A., SANDU, I., Instrumentation Science \& Technology, 43, 2015, p. 545.

6.SANDU, A. V., CIOMAGA, A., NEMTOI, G., BEJ INARIU, C., SANDU, I., Microsc. Res. Tech., 75, 2012, p. 1711.

7.SANDU, A.V., BEJ INARIU, C., NEMTOI, G., SANDU, I.G., VIZUREANU, P., IONITA, I., BACIU, C., Rev. Chim.(Bucharest), 64 no. 8, 2013, p. 825.

8.BUZEA, C.G., BEJ INARIU, C., BORIS, C., VIZUREANU, P., AGOP, M., Int. J. Nonlinear Sci.Numer. Simul., 10, 2009, p. 1399

9.LEVCOVICI, M.S., Studiul materialelor I, Ed. Fundatiei Universitare Dunarea de Jos, Galati, 2002. 
10.POTECASU, F., Metalurgie fizica, vol 1, Ed. FRM, Bucuresti, 2007. 11.NEJ NERU, C., VIZUREANU, P., SANDU, A.V., GRECU, A., CIMPOESU, N., Rev. Chim. (Bucharest), 65, no. 2, 2014, p. 194.

12.PAPADATU, C.P., SANDU, A.V., BORDEI, M., SANDU, I.G., Rev. Chim. (Bucharest), 68, no. 4, 2017, p. 675.

13.PAPADATU, C.P., SANDU, A.V., BORDEI, M., SANDU, I.G., Rev. Chim. (Bucharest), 68, no. 10, 2017, p. 2329.

14.PAPADATU, C.P., SANDU, I.G., BORDEI, M., NABIALEK, M., SANDU, A.V., Mat. Plast., 53, no. 4, 2016, p. 771.

15.PAPADATU, C.P., SANDU, A.V., BORDEI, M, SANDU, I.G., Rev. Chim.(Bucharest), 67 no. 11, 2016, p. 2306.
16.RIPOSAN, I. SI SOFRONI, L.. Fonta cu grafit vermicular, Ed. Tehnica Bucuresti, 1984.

17.SOFRONI, L., RIPOSAN, I., BRABIE, V. , CHISAMERA, M., Turnarea fontei, Ed. Didactica si Pedagogica, Bucuresti, 1985.

18.JUKOV, A.A., Fe-C. The stable and metastable equilibria. GiessereiForschung, 44, 1992, p.106.

19.DUMITRESCU, T., Diagrama de echilibru metastabil Fe - C, Ed. Universitatea Dunarea de J os, Galati, 1988.

20.DUMITRESCU, T., Diagrama de echilibru stabil Fe - C, Ed. Universitatea Dunãrea de Jos, Galati, 1989

$\overline{\text { Manuscript received: } 15.07 .2017}$ 